\title{
CONSTRUCTION OF PRECAST CONCRETE SHELLS IN GEORGIA
}

\author{
MOSHE DANIELI \\ Department of Civil Engineering, Ariel University, Israel
}

\begin{abstract}
Constriction of monolithic concrete shells requires the creation of costly, time-consuming formwork. The means of solving this problem is the construction of precast reinforced concrete shells. Since the second half of the 20th century construction of precast reinforced concrete shells started (over $30 \mathrm{~m}$ in span) in Georgia. Their number exceeds 40. These include: Bath building no. 8 dome cover (1956) in Tskhaltubo resort town (span of dome $2 \mathrm{R}=40 \mathrm{~m}$, rise $\mathrm{f}=3.2 \mathrm{~m}$, effective thickness $\mathrm{t}=0.15 \mathrm{~m}$ ), the dome cover of the sports hall (1958) in Tbilisi (span of dome $2 \mathrm{R}=76 \mathrm{~m}$, rise $\mathrm{f}=13.5 \mathrm{~m}$, effective thickness $t=0.15 \mathrm{~m}$ ), dome covers of reservoirs (1962-1972) in Tbilisi (for water), Gardabani (for fuel oil) (span of dome $2 \mathrm{R}=40 \mathrm{~m}$, rise $\mathrm{f}=3.8 \mathrm{~m}$, effective thickness $\mathrm{t}=0.15 \mathrm{~m}$ ) and others, squarein-plan precast-monolithic dual curvature cover (1982) in the city of Sukhumi (side of the square L = $40 \mathrm{~m}$, rise $\mathrm{f}=8.0 \mathrm{~m}$, effective thickness $\mathrm{t}=0.10 \mathrm{~m}$ ), and others. Structure of these covers and uniqueness of their construction drew attention in Georgia. Despite this, due to the novelty of precast construction and specifically the precast shells, during the operation period some cracks appeared and significant deformation developed; there were even cases of collapse. The article presents and summarizes the experience of precast and precast monolithic concrete shells construction in Georgia. It describes typical defects of precast reinforced concrete shells that appeared during the operation. We survey the reasons for the collapse of the tank ceiling dome and demonstrate the enhancement of shell reliability by using the replacement of the roofing coverage.

Keywords: shell, concrete, precast, precast-monolithic, deformation, reliability.
\end{abstract}

\section{INTRODUCTION}

In the construction of civil and industrial buildings the most various forms of shells are widely used. The first large covering was a stone dome. Currently there are many stone domes all over the world. As a rule, they are architectural works of art. Their preservation is the responsibility of a civilized society. At the end of the 19th century concrete appeared. With its appearance heavy stone domes were replaced by more lightweight concrete domes. Later the construction of reinforced concrete shells of various forms was developed. In the 20th century one of the rational kinds of spatial coverages was a reinforced concrete shell.

The widespread use of concrete shells for coverings began in Germany. Later on, their construction developed in other countries of Europe, in the United States, Japan, etc. Originally, their span did not exceed $20 \mathrm{~m}$, effective thickness was $10-15 \mathrm{~cm}$ and more. Generally, they were implemented of monolithic reinforced concrete on solid, mostly wooden, formwork. The most common covering worldwide is that with a span of 30 to $60 \mathrm{~m}$. Today there are reinforced concrete shells with a span over $200 \mathrm{~m}$. Spans of reinforced concrete vary widely. The first to the known author concrete dome which was built in Georgia, is a spherical concrete dome of the covered Hall of the Synagogue (former) of European (Ashkenazi) Jews in Tbilisi (now of the D. Baazow Historical - Ethnographic museum of Jews in Georgian), was built in 1915 (span of dome: diameter $2 \mathrm{R}=15 \mathrm{~m}$, rise $\mathrm{f}$ $=7.0 \mathrm{~m}$, thickness $\mathrm{t}=0.15-0.2 \mathrm{~m}$ (Fig. 1) [1]. 
Since 1940 construction of monolithic reinforced concrete shells with relatively small spans has been widely developing in Georgia. With respect to the construction of largespan monolithic concrete shells (span of more than $30 \mathrm{~m}$ ) it was necessary to prepare a costly, time-consuming formwork. In connection with this, there was the need to reduce time-consuming work on the construction site, as well as to reduce the cost of building envelopes. The means of solving the problem was the construction of precast reinforced concrete shells that was preceded by a wide experience in the construction of monolithic concrete shells.

Since the second half of the 20th century the construction of precast reinforced concrete shells (with a span over $30 \mathrm{~m}$ ) began. Improvement of quality of building materials, cement and steel and industrialization of construction, as well as the development of shell calculation theory, promoted this construction. Negative factors for the development of shell construction are: complexity of their erection, high cost and complexity of metal formworks manufacture and implementing the joints of precast elements. In connection with this wide development of construction of precast shells without supporting scaffolds began. To the best of the author's knowledge, covered market in Algeria (1950) and the cover of Kiev circus, the span - $40 \mathrm{~m}$ (1955), are the predecessors of construction without supporting scaffolds [2].

Beginning with 1950s construction of precast shells started in Georgia. Their number exceeded 40. Of this number we note the following: bath building no. 8 dome cover (1956) in the resort town of Tskhaltubo (span of dome: diameter $2 \mathrm{R}=40 \mathrm{~m}$, rise $\mathrm{f}=3.2 \mathrm{~m}$, effective thickness $t=0.15 \mathrm{~m}$ ), the dome cover of the sports hall (1958) in Tbilisi (span of dome: diameter $2 \mathrm{R}=30 \mathrm{~m}$, rise $\mathrm{f}=2.1 \mathrm{~m}$, the effective thickness $\mathrm{t}=0.15 \mathrm{~m}$ ), the dome cover of the Sports Palace (1960) in Tbilisi (span of dome: diameter $2 \mathrm{R}=76 \mathrm{~m}$, rise $\mathrm{f}=$ $13.5 \mathrm{~m}$, effective thickness $\mathrm{t}=0.15 \mathrm{~m})$, dome covers of reservoirs (1962-1972) in Tbilisi (for water), Gardabani (for fuel oil), (span of dome: diameter $2 \mathrm{R}=40 \mathrm{~m}$, rise $\mathrm{f}=3.8 \mathrm{~m}$, effective thickness $\mathrm{t}=0.15 \mathrm{~m}$ ) [1]-[4], square-in-plan precast monolithic dual curvature cover of the market building (1982) in the city of Sukhumi (side of the square L $=40 \mathrm{~m}$, rise $\mathrm{f}=8.0 \mathrm{~m}$, the thickness $\mathrm{t}=0.10 \mathrm{~m}$ ) [5] and others.

It should be noted, that the design of these covers and the uniqueness of their construction in Georgia drew attention to developed and refined designs, methods of calculation and erection of precast shells. Some of these buildings were designed and built with the direct participation or consultation of the Institute of Structural Mechanics and Seismic Resistance of the Georgian Academy of Sciences (ISMEE) (1948-2008), (Academicians K.S. Zavriev, O.D. Oniashvili, Ph Doctors Sh.A. Djabua, N.V. Akhvlediani, V.N. Shaishmelashvili et al) [6]. As a result of cooperation with the authors, design and construction engineers' safety of this structure was provided. Despite this, due to the novelty and specificity of precast shell construction, on expiry of time incidents, such as cracks and significant deformations, appeared in some of these shells. There was case of collapse.

The article presents and summarizes the experience of the construction of modular and precast monolithic concrete shells in Georgia. It describes typical defects of precast reinforced concrete shells that appear during the operation. The reasons of the collapse of the tank ceiling dome are analysed. Examples are given: spherical dome reliability enhancement with the help of roofing coverage replacement and increase of seismic resistance by using embedment of the joints in precast elements. 


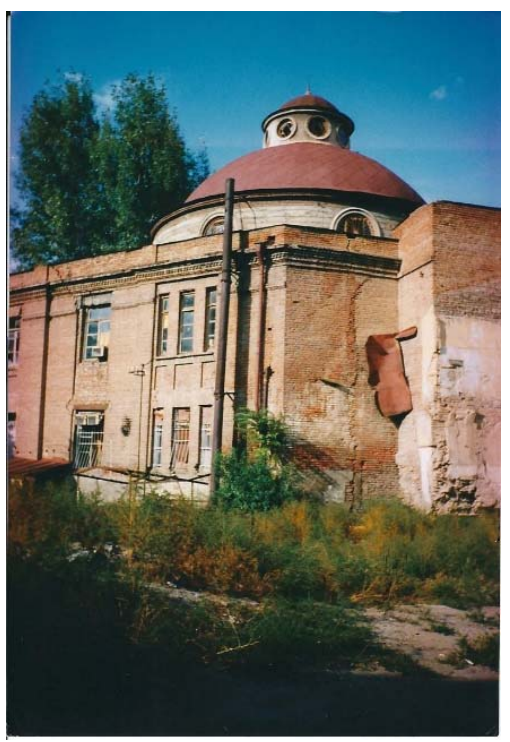

(a)

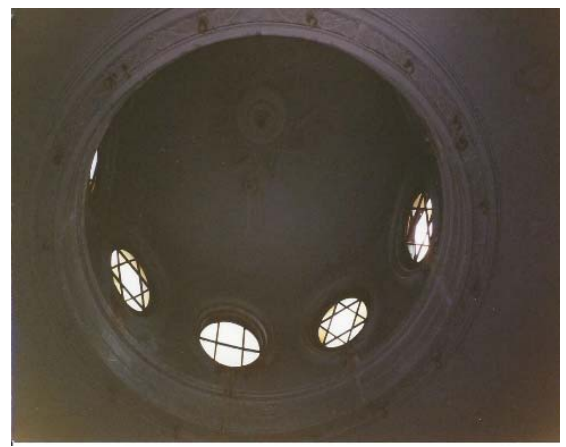

(b)

Figure 1: The Synagogue (former) of European (Ashkenazi) Jews in Tbilisi, (now of the D. Baazow Historical - Ethnographic museum of Jews in Georgian). a) General view; b) Interior of Dome.

\section{PRECAST CONCRETE DOMES}

\subsection{Dome cover bath building No. 8 (1956) in the resort town of Tskhaltubo}

Dome with a span of bath building no. $8-40 \mathrm{~m}(2 \mathrm{R}=40 \mathrm{~m}, \mathrm{f}=3.18 \mathrm{~m}, \mathrm{~h}=0.15 \mathrm{~m}$, where $\mathrm{R}$ is the radius of projection, $\mathrm{f}-$ the rise, $\mathrm{h}-$ effective thickness) (Fig. 2). The shell is assembled of steplike plates of permanent thickness without suspending scaffolds. Within the shell there is a hole of $10 \mathrm{~m}$ in diameter for ventilation and light. Authors of the structure: D. Kadjaya, N. Meskhi (Fig.2) [2], [4].

\subsection{The dome structures of the sport hall in the city of Tbilisi (1958) [2], [4]}

The dome structures of the sport hall made of precast reinforced concrete plates, span -30 $\mathrm{m}(2 \mathrm{R}=30 \mathrm{~m}, \mathrm{f}=2.10 \mathrm{~m}, \mathrm{~h}=0.15 \mathrm{~m})$. The engineering solution of this dome assembled of steplike ribbed plates has been a basis for the precast dome cover of the Sports Palace in the city of Tbilisi.

\subsection{The dome structures of the Sports Palace in the city of Tbilisi (1960) [3]}

The dome structures of the Sports Palace made of precast reinforced concrete plates, span $76 \mathrm{~m}(2 \mathrm{R}=76 \mathrm{~m}, \mathrm{f}=13.5 \mathrm{~m}$, effective thickness $\mathrm{h}=0.15 \mathrm{~m})$. The erection work has been carried out without suspending scaffolding. The design of the dome cover is solved by way of shaping a steplike profile to the precast plates. This makes it possible to fix the circular plates assembled previously. A drawback of this erection work consists in the availability of a double-layer plate (Fig. 3). 


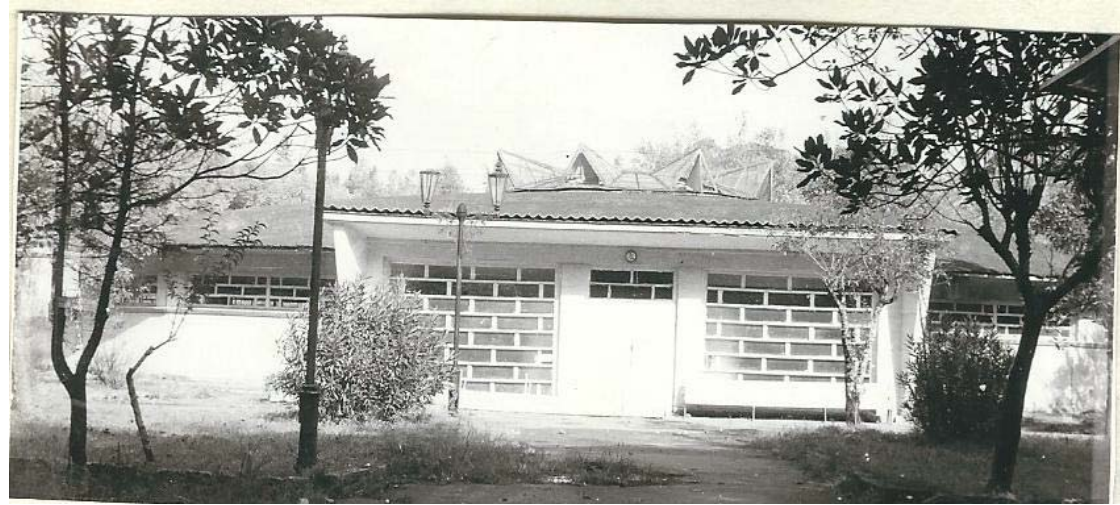

(a)

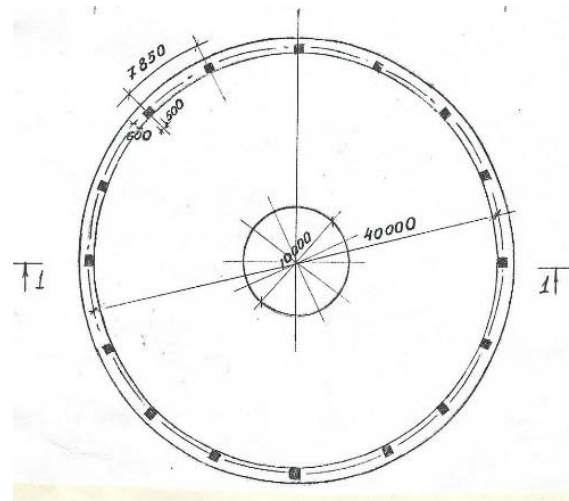

(b)

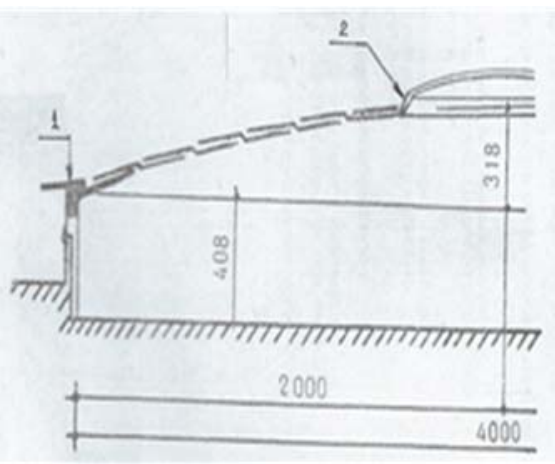

(c)

Figure 2: Dome cover of the Bath Building no. 8 in Tskhaltubo. (a) General view; (b) Schematic plan; (c) Schematic section; (1) Contour band; (2) Monolitic band.

\subsection{Construction of a fuel oil reservoir cover near the city of Tbilisi, Gardabani}

The same method which was used in the erection of the Sports Palace, was applied in the construction of the dome of the fuel oil reservoir near the city of Tbilisi (Gardabani regional power station) $2 \mathrm{R}=40 \mathrm{~m}, \mathrm{f}=3.3 \mathrm{~m}$, effective thickness $\mathrm{h}=0.15 \mathrm{~m}$ [1]. The dome rests on a precast cylindrical reservoir. It should be noted that the shallowness of the oil reservoir dome is 2.5 times more as compared with the Sports Palace. Despite sufficient bearing capacity (in conditions of joint work of structural elements and uniform strength of the units of joints with the precast elements) on expiry of 12 years of operation collapse (1976) of the dome-shaped cover of the fuel oil reservoir occurred. View of the collapsed dome of the fuel oil reservoir of Gardabani regional power station is given in Fig. 4. It should be noted that the shallowness of the oil reservoir dome is 2.5 times more as compared with the Sports Palace.

\subsection{Precast reservoirs for water}

Another type of precast reservoirs for water, also with a span $2 \mathrm{R}=40 \mathrm{~m}$, whose dome is assembled of flat precast plates is rather widely spread. Erection of precast plates is 


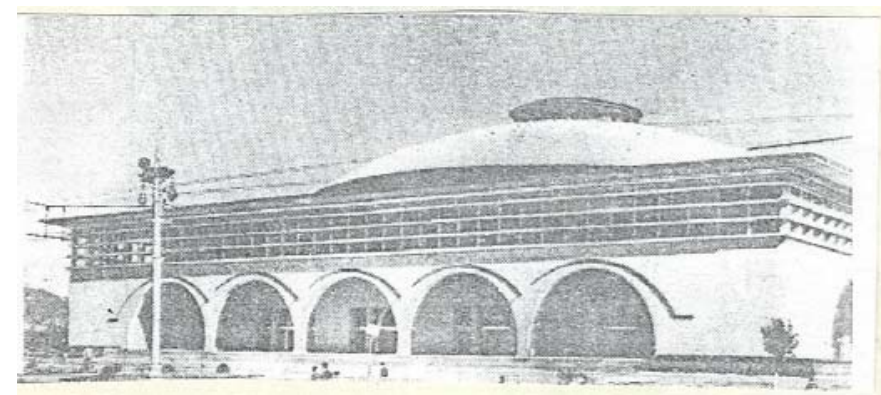

(a)

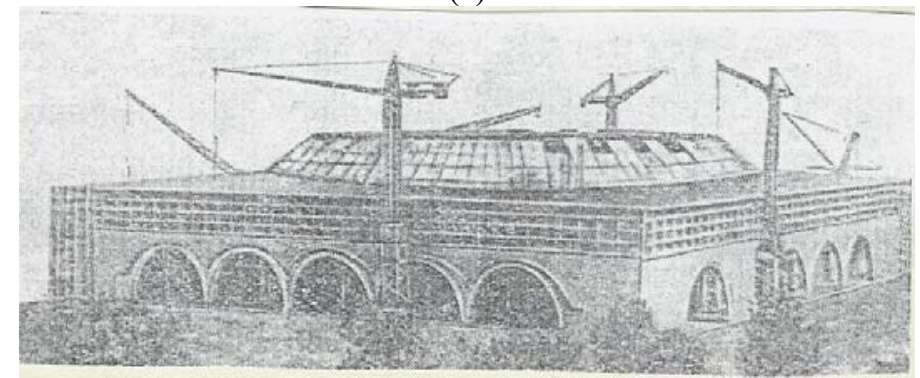

(b)

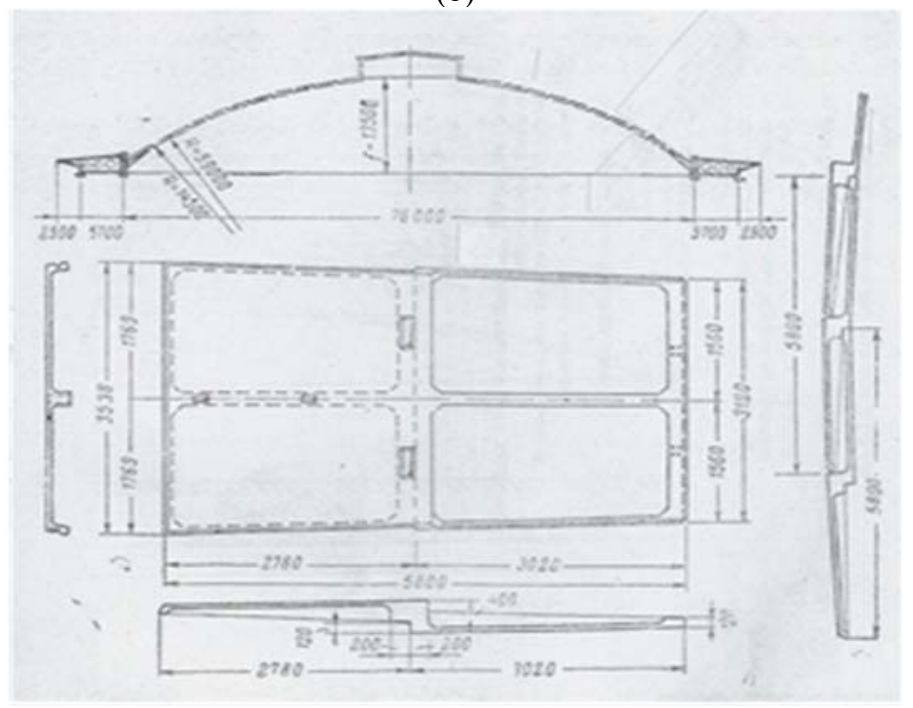

(c), (d), (e)

Figure 3: Dome of the Sports Palace in Tbilisi. (a) General view; (b) Stage of dome mounting; (c) Cross section; (d) Fragment of the longitudinal section; (e) Precast plate with cross and longitudinal section.

performed by means of unique arrangement of precast flat plates that resembles the shape of teeth. In connection with this method of plates erection was named a "toothed technique" (Fig. 5) [2], [4]. Due to such technique of erection the necessity of using a complicated profile and double-layer solution of shell thickness was ruled out. This type is well examined both at the stage of erection (Gabrichidze and Saghirashvili [7]) and at the operation 
stage (Akhvlediani [8], Danielashvili [9]) with consideration for seismic resistance problems (A. Melikyan) [1].

\subsection{The cylindrical shells}

In 1960-s two cylindrical shells for covering the service area were erected in Tbilisi television building, dimensions in plan being $15 \times 20$ and $20 \times 30 \mathrm{~m}$. These shells were built of precast flat ribbed plates with the aid of the toothed technique. On expiry of certain time the shell $(15 \times 20 \mathrm{~m}$ in plan) of flat ribbed plates collapsed. The collapse occurred during the repair work of the roof cover due to significant one-sided loading with building materials used for repair. The author of these structures is engineer D. Kadjaya [2].

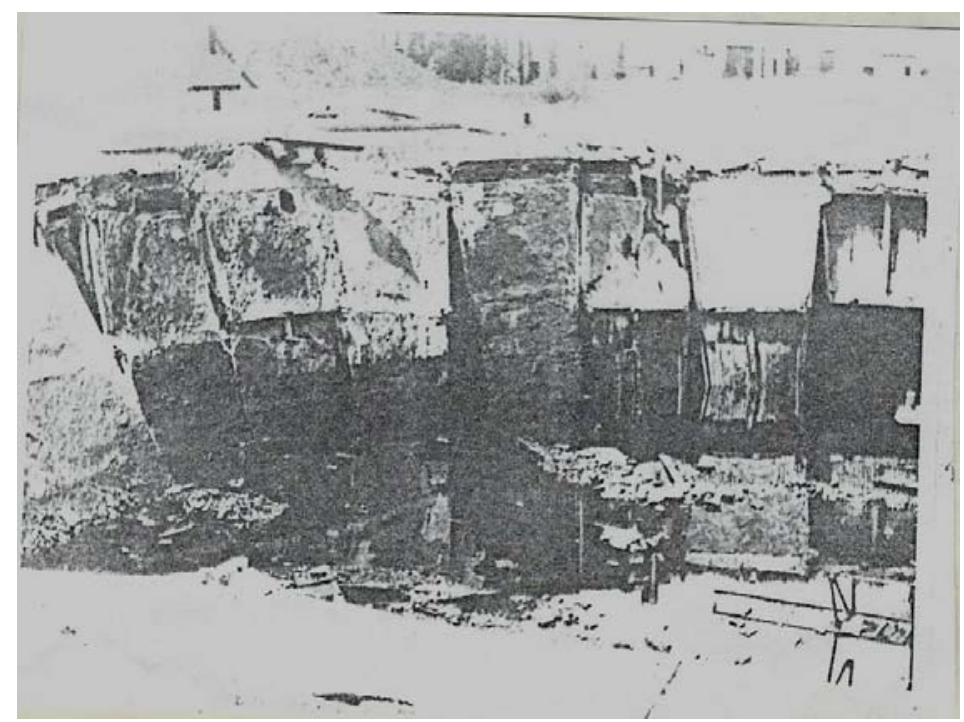

Figure 4: Failure of the dome of the fuel oil reservoir.

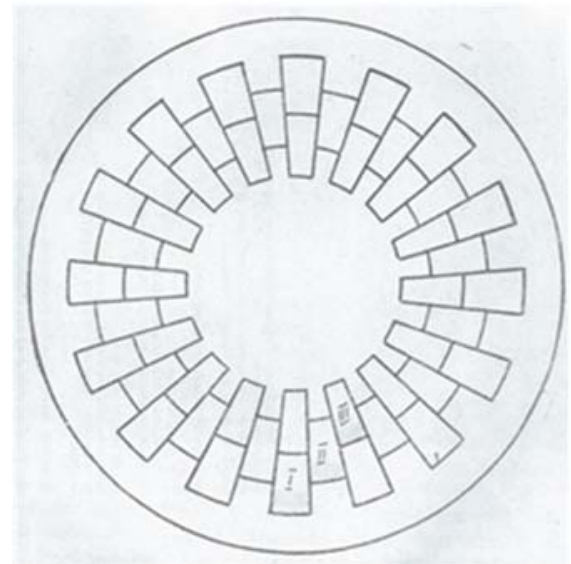

Figure 5: Layout of erection by means of the "toothed technique" - section no. I, II, III 


\section{ANALYSIS OF SHELLS BEHAVIOR}

\subsection{Sports Palace in Tbilisi (Fig. 3)}

It should be mentioned, however, that in the course of operation it became obvious that due to shell temperature deformation dome soft roofing of the Sports Palace along joints between the precast elements were rupturing. In these points, moisture penetrated in the bearing structures resulting in corrosion of connection steel elements and decrease of concrete resistance in the points of joints. In connection with this, the soft roof with a warmth-keeping jacket was removed (800 tons of roof covering and warmth-keeping jacket) which corresponds to $150 \mathrm{~kg} / \mathrm{m}^{2}$. Roof soft covering was replaced by metal roofing sheets. By virtue of these actions the covering of the Sports Palace was substantially unloaded.

\subsection{Bath building no. 8 in Tskhaltubo (Fig. 2)}

Since the covering did not ensure the Bath building protection from the penetration of atmospheric precipitation, it might cause the loosening of concrete joints. In the precast dome-shaped roofs of the bath building no. 8 in Tskhaltubo corrosion is observed in the reinforcement rods of plates from the aggressive medium within the bath building. Systematic protection of reinforcement rods against corrosion, as well as protection from increased humid aggressive medium due to evaporation of mineral radon water is required.

\subsection{Dome of the fuel oil reservoirs (Fig. 4)}

Despite sufficient bearing capacity (in conditions of joint work of structural elements and uniform strength of the units of joints with the precast elements) of the oil reservoirs, on expiry of 12 years of operation collapse (1976) of the dome cover of the fuel oil reservoir occurred (Fig. 4). The collapse is conditioned by the increase of time warping and the roof itself which is rather shallow $(\mathrm{f} / 2 \mathrm{R}=1 / 12)$. The increase of deformation took place due to geometry distortion during the erection, insufficient quality of embedment of joints and, as a result, lack of joint action of the reservoir dome and cylindrical reservoir wall. At the same time, it should be noted, that two similar reservoirs are presently in service. It should be noted also, that shallow shells are very sensitive to movement which may cause the development of nonlinear deformations, and for this reason, the designing of shallow shells should be treated with special attention.

For calculating the carrying capacity of the considered shells a theory of limit equilibrium (limit analysis) was successfully applied [8]-[10].

\section{PRECAST - MONOLITHIC DUAL CURVATURE SHELL COVER IN SUKCHUMI}

\subsection{Structure of the shell}

A precast monolithic spherical reinforce-concrete shell square in plan overlapping the central hall of the new market has been erected in the city of Sukhumi (Fig. 5) [5]. The shell design has been developed by the Institute of Structural Mechanics and Earthquake of the Georgian Academy of Sciences, Design Institute no1 of Leningrad, the Georgian Department of Giprotorg. Due to seismicity of the construction area provision was made for increasing the degree of embedment aimed at greater approximation to the work conditions of a monolithic structure and enhancement of the structure rigidity. Shell dimensions in 
plan are $40 \times 40 \mathrm{~m}$, the surface is spherical and the rise is equal to $7.6 \mathrm{~m}$ (Fig. 6(a)). The main part of the cover confined in plan by a circumference of $40 \mathrm{~m}$ in diameter, is assembled of two rows of precast reinforced concrete ribbed plates with inflexions near the circular ribs with subsequent embedment of joints between these ribs (Fig. 6(b)). Division of the shell into precast elements and monolithic sections is given in Fig. 7. Longitudinal and extreme cross ribs of $30 \mathrm{~cm}$ in height and variable width on the outer surface are fitted with grooves measuring $10 \times 20 \mathrm{~cm}$ and $1.5 \mathrm{~cm}$ in depth. Thickness of plate flanges is 4 and 5 $\mathrm{cm}$. The plate ribs are reinforced with one-fold frames, flanges - with unitary nets. The dome drum of $6 \mathrm{~m}$ in diameter is reinforced with radial beams; angular zones and contour band are made of monolithic concrete (Fig. 7). Contour diaphragms are made of steel trusses transmitting load to monolithic reinforced concrete columns of $9.5 \mathrm{~m}$ in height and $90 \times 90 \mathrm{~cm}$ in cross-section. The angular zones are strengthened with meridional ribs and reinforced with dual nets whose pins are directed to the contour band at the angle of $45 \mathrm{deg}$. and are welded to the upper band of the contour diaphragms. Plate thickness of the monolithic portion is $10 \mathrm{~cm}$ near the band and $8 \mathrm{~cm}$ near the precast plates, the height of plate ribs is $30 \mathrm{~cm}$. The contour band whose height is $35 \mathrm{~cm}$ is reinforced by a continuous three-dimensional carcass over the entire contour of the shell, thus forming a closed band for the shell and is bound by welding with the upper band of the contour frameworks whose bearing parts are also connected by welding.

With the purpose of creating a single meridional-circular, continuous reinforcement carcasses were placed in circular and radial joints between the plates, and the reinforcement of the circular and meridional ribs is bound by welding. The carcasses of plate meridional ribs are also bound with the carcasses of ribs of the monolithic part of the angular zones. In this way, a single reinforced-concrete meridional-circular carcass connected with the contour diaphragms has been created within the shell.

\subsection{Design data of shell cover}

A design grade of concrete of the precast plates, monolithic sections, for filling joints between the plates and columns, is M300. For the shell roofing use was made of galvanized roof steel. The cover is designed on the basis of the moment theory of shells with consideration for Eberhard effect in accordance with [11] for design load of $40 \mathrm{MPa}$. The critical load for stability is $60 \mathrm{MPa}$, and the limit load in compliance with the theory of limit equilibrium according to [12], [13] amounts to $54 \mathrm{MPa}$. Rated forces in the shell from a special combination of loads with consideration for seismic effect of the ground's predicated horizontal acceleration $\boldsymbol{a}_{h, \max }=0.75 \mathrm{~m} / \mathrm{s}^{2}$ with application of coefficients of combinations $N c=0.9$ for constant load and $N c=0.5$ for snow load, as well as in [14], are not limiting ones.

The roof shell is characterized by the following engineering-and-economic performance: concrete consumption $-160 \mathrm{~m}^{3}$, reinforcement steel for the shell -21.2 tons (for $1 \mathrm{~m}^{2}$ of the overlapping area $-0.1 \mathrm{~m}^{3}$, of concrete and $13.4 \mathrm{~kg}$ of steel accordingly) quantity of profiled steel for 4 contour diaphragm trusses is 44 tons.

\subsection{Erection of the shell}

Precast plates are made in two metal frameworks by method of vibration. The moulds are fitted with cells for steam curing. The plates of the shell were placed in design position with the use of metal inventory scaffolds of post-and-beam type by means of a tower crane mounted previously in the shell centre. The shell in the process of erection is given in Fig.5 


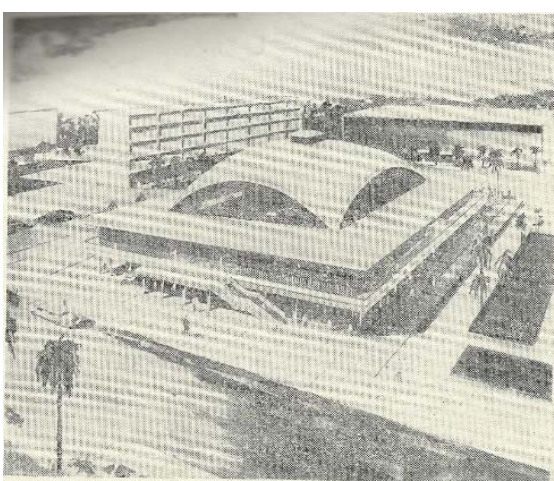

(a)

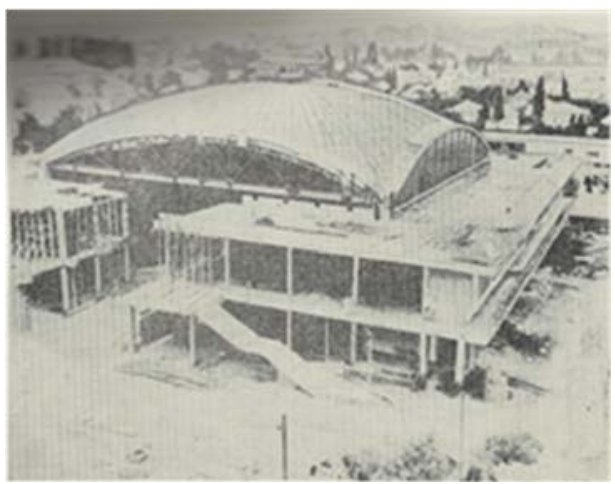

(b)

Figure 6: Dual Curvature Shell cover in Sukhumi. (a) Model; (b) View in the process of erection.

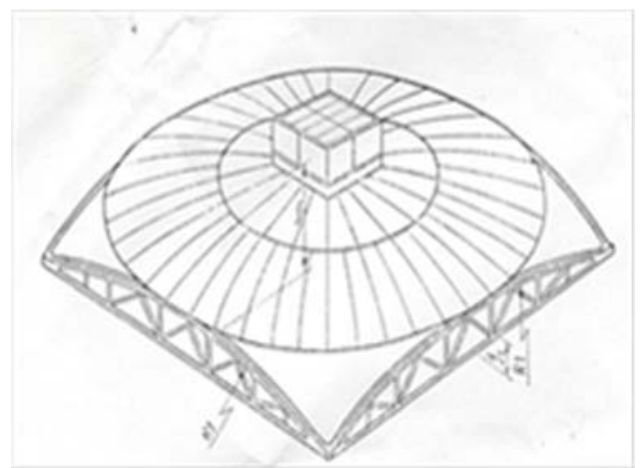

(a)

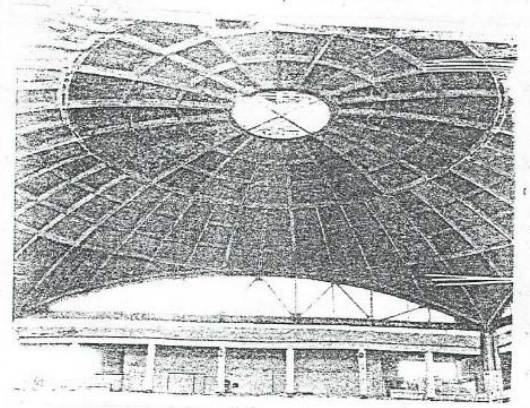

(b)

Figure 7: (a) Shell surface; (b) Bottom view.

The posts of the inventory scaffolding rested on sandboxes. After placing the plates of two rows on one half of the shell a framework was erected for monolithic sections in two angular zones, between the precast plates under the joints a framework was suspended, rows on one half of the shell a framework was erected for monolithic sections in two angular zones, between the precast plates under the joints a framework was suspended, corresponding reinforcement was installed and concrete was placed. The concreting was implemented by continuous vibration. After that the tower crane was carried away from the shell zone, and the second half of the shell was erected in a similar way. On expiry of 28 days after the concreting of the second stage the posts of the inventory scaffolding were lowered in stepwise manner (in 5 steps) by removing sand from the sandboxes. By the moment of releasing the shell from the scaffolds the strength of the concrete of the precast plates determined by a cube crushing test and reference hammer hesitated within the limits of 30 to $40 \mathrm{MPa}$, the strength of the monolithic section placed was near $40 \mathrm{MPa}$. The strength of concrete of the columns amounted to $40 \mathrm{MPa}$. 


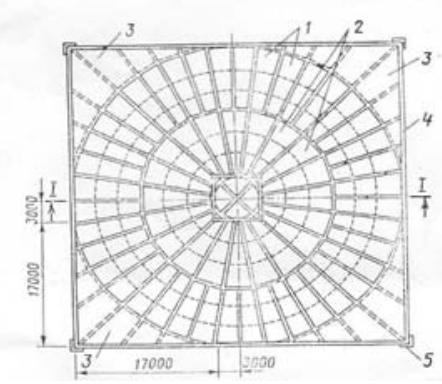

(a)

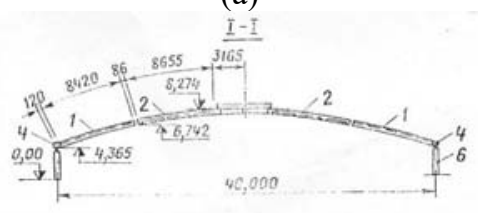

(b)

Figure 8: Division of the shell into precast elements and monolithic sections. (a) Plan; (b) Section. 1 - plates of the first row covering; 2 - plates of the 2nd row covering; $3-$ angular monolithic zones; 4 contour band; 5 reinforced concrete column; 6 - contour truss.

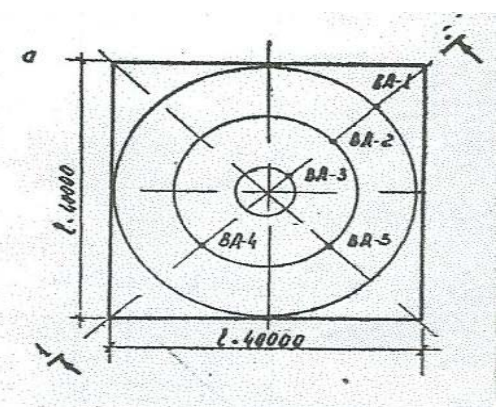

(a)

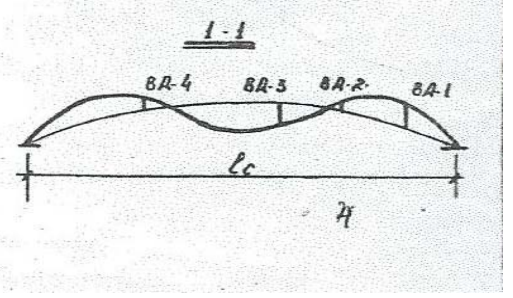

(b)

Figure 9: (a) Diagram of arrangement of vibration detectors; (b) Form of low tone oscillations.

\subsection{Natural experimental study}

\subsubsection{Static study}

In the process of the decentring measurements of shell and contour diaphragm trusses flexing were performed, as well as horizontal and vertical movements of the mounting groups of the contour diaphragm trusses [15]. Location of deflect meters made it possible to control the uniformity of coming into action of all parts of the shell. Maximum deflection from the proper weight in the shell centre was equal to $27 \mathrm{~mm}$, on the middle of the truss span $-20 \mathrm{~mm}$. Relative values of these deflections (1/1480 and 1/2000) bear record to sufficient rigidity of the shell. Vertical movements of the mounting groups of the diaphragm trusses reached $1 \mathrm{~mm}$ and the divergence of the mounting groups in the plane of a diaphragm truss $-13.65 \mathrm{~mm}$, which corresponds to the tensile strength in the lower band - $72 \mathrm{MPa}$. This value is approximate to the design stress from the shell proper weight determined according to [11] and equal to $94 \mathrm{MPa}$. After the removal of the supporting scaffolding no cracks or other local defects were detected. 


\subsubsection{Study of the dynamic characteristics}

The dynamic characteristics of the shell were examined experimentally [15]. Oscillations were excited by vertical and horizontal pulses concentrated in the shell centre (by sudden removal of a load of $500 \mathrm{~kg}$ in weight). In doing so vertical free oscillations of the shell were recorded with the aid of graph plotter H338-6П and vibration detectors VEGIK installed on the shell surface (Fig. 8(a)). As a result of analysing the oscillograms a threehalf-wave of the form of low-tone free oscillations across the shell diagonal section was determined (Fig. 8(b)), frequency $f=8 \mathrm{~Hz}$ and logarithmic decrement $\lambda=0.15$. The obtained value of frequency is approximates the theoretical one $(f=9.8 \mathrm{~Hz})$ determined according to [16] for monolithic shells. At the same time, it exceeds, by $30 \%$ on the average, the experimental values of frequency $f$ given in [14] for similar precast shells. As a result of the tests, it was established that the degree of concrete embedment of a precast-monolithic shell is high enough which is important from the point of view of its seismic stability.

\section{RECOMMENDATIONS FOR CONSTRUCTION OF PRECAST CONCRETE SHELLS}

As far as it is known to the author after 1980 construction of precast shells was not implemented in Georgia due to certain changes in the economic conditions and in the industry of buildings.

For future construction of precast shells, the author recommends the following:

- Shells actually are continual systems. In connection with this, it is recommended to achieve maximum approximation of properties of precast shells to those of monolithic shells.

- $\quad$ To try to use the least quantity of various precast elements.

- To protect shells from the penetration of atmospheric precipitation, since it may cause destruction of concrete in the joints and corrosion of metal embedded parts. Destruction of concrete is dangerous, since the main part of the shell is in compressed state.

- For roof covering use should be made of materials which ensure protection from penetration of atmospheric water regardless of temperature action and shell deformation, e.g. metal roofing.

- For ensuring the reliability for rather shallow shells (ratio $f / 2 R<1 / 10$ ) it is recommended to perform calculations with consideration for nonlinear moment theory.

\section{ACKNOWLEDGEMENTS}

The author dedicates this article to the memory of those outstanding scientists of the Institute of Structural Mechanics and Seismic resistance of the Georgian Academy of Sciences (1948-2008), who have passed away: Academicians K. S. Zavriev, O. D Oniashvili, Ph Doctors Sh. A. Djabua, V. N., N. V. Akhvlediani, V. N. Shaishmelashvili, Doctor of Sciences L. Mukhadze et al and also outstanding engineer D. I. Kadzhaya, who made a great contribution to the development of test calculations the in the construction of shells in Georgia.

\section{REFERENCES}

[1] Danielashvili, M.A., Study in reality condition of reinforced concrete shells of floors and coverage spreading in Georgia and the Calculation method of evaluation of their load carrying capacity, Institute of Structural Mechanics and Earthquake 
Engineering of the Academy of Science of the Rep. of Georgia (ISMEE), p. 57, Tbilisi, 1995, (in Georgian).

[2] Berishvili, I., Modern thin-walled spatial structures, Sovetskaya Gruzia: Tbilisi, p. 152, 1972, (in Georgian).

[3] Kadjaya, D.N., The precast spherical dome of the Sports Palace cover in Tbilisi and its erection without scaffolding. Beton i Zhelezobeton, (10), pp. 9-10, Moscow, 1966, (in Russian).

[4] Kadjaya, D.N. \& Bernshvili, I.S., Precast reinforced concrete shells erected without supporting scaffolding. 6th conference on concrete and reinforced concrete, Riga, pp. 58-62, 1966.

[5] Akhvlediani, N.V., Danielashvili, M.A., Djabua Sh.A., Lejiava, G.I., Shapiro. A.V. \& Gegecthkori, M.N., The shell roof of Sukhumi Central Market. Beton $i$ Zelezobeton,(10), pp. 6-7, Moscow, 1983 (in Russian).

[6] Oniashvili, O.D., Design of shells and other in-walled spatial structures. Structural Mechanics in USSR 1917-1967. Gosstroiizdat, Moscow, pp. 90-120, 1969 (in Russian).

[7] Gabrichidze, G.K. \& Sagirashvili, L.I., Calculation of open domes, Concrete and Reinforced Concrete, 2, Metsniereba: Tbilisi, pp. 129-135, 1968, (in Russian).

[8] Akhvlediani, N.V., Design of reinforced concrete domes by the method of limit equilibrium. Studies of the theory of structures, 10, Gosstroiizdat: Moscow, pp. 127132, 1961, (in Russian).

[9] Akhvlediani, N.V. \& Danielasvili, M.A., Limit Analysis of Reinforced Concrete Shells. Archiwum Inz. Ladowe, 36(3), Warsaw, Poland, pp. 187-205, 1990.

[10] Danieli, D., Limit Analysis of Reinforced Concrete Shells of Revolution and Its Application. Proceedings of the Ninth International Conference on Civil and Structural Engineering Computing, (58), eds B.H.V. Topping, Civil-Comp Pres:, Sterling, Scotland, pp. 1-20, 2003.

[11] Instruction manual on design of the reinforced concrete space coverings and floor structures, Stroiizdat: Moscow, p. 320, 1979, (in Russian).

[12] Akhvlediani, N.V. \& Shaishmelashvili, V.N., On calculation the load carrying capacity of the shells. Bulletin the Academy of Sciences of Georgian SSR, 13(10), Metsniereba: Tbilisi, pp. 130-134, 1952, (in Russian).

[13] Akhvlediani, N.V., On calculation the load carrying capacity of shallow reinforced concrete shells of dual curvature. Studies of the theory of structures, 2, Gosstroiizdat: Moscow, p.78-86, 1962, (in Russian).

[14] Bobrov, F.V., Bykhovski, V.A. \& Gasanov, A.N., Seismic loads on shells and suspended covers, Moscow, Stroiizdat, p. 144, 1974.

[15] Akhvlediani, N.V, Danielashvili, M.A. \& Djabua, Sh.A., et al., Full-scale tests of Built-up monolithic reinforced concrete shells of double curvature. Bulletin of the Academy of Sciences of Georgian SSR, 111(3), Metsniereba: Tbilisi, pp. 553-556, 1983, (in Russian).

[16] Oniashvili, O.D., Some dynamic problems of the theory of shells, Moscow Publishing: House of the USSR Academy of Sciences, p. 320, 1957. 